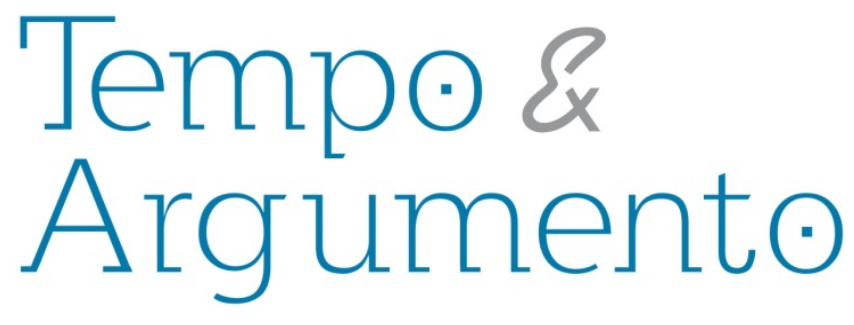

\title{
Marco Civil: Liberdade e o Futuro da Internet
}

\section{Resenha da obra:}

ASSANGE, Julian. Cypherpunks: liberdade e o futuro da internet. Trad. Cristina Yamagami. São Paulo: Boitempo, 2013.

Autores:

\section{Ramon Trindade Pellegrini}

Mestrando do Programa de Pós-Graduação em Memória: Linguagem e Sociedade, da Universidade Estadual do Sudoeste da Bahia; compõe o quadro de pesquisadores do Grupo de Estudos de Ideologia e Lutas de Classe (Geilc), bolsista da Capes/CNPq.

$$
\text { Brasil }
$$

ramonpellegrini1@gmail.com

\section{Rafael Trindade Pellegrini}

Graduando em História pela Universidade Estadual do Sudoeste da Bahia (Uesb); compõe o quadro de pesquisadores do Grupo de Pesquisa Natureza, Cultura e Complexidade, bolsista da Capes/CNPq.

$$
\text { Brasil }
$$

rafatpellegrini@gmail.com

\section{Para citar esta resenha:}

PELLEGRINI, Ramon Trindade; PELLEGRINI, Rafael Trindade. Marco Civil: Liberdade e o Futuro da Internet. Revista Tempo e Argumento, Florianópolis, v. 6, n.12, p. 265 - 270, mai./ago. 2014. 
Cypherpunks: liberdade e futuro da internet, publicado pela Editora Boitempo, no ano de 2013, é uma obra criada a partir das reflexões de Julian Assange, em parceria com Jacob Appelbaum, Andy Müller-Maguhn e Jérémie Zimmermann, fruto dos debates registrados no programa The World Tomorrow ${ }^{1}$, apresentado pelo próprio Assange. Um livro que suscita a reflexão sobre a vigilância de informações pela internet por parte dos governos, principalmente o estadunidense. Nas palavras do autor, este exemplar "não é um manifesto, não há tempo para isso [trata-se de] um alerta" (ASSSANGE, 2013, p. 25), pois o futuro do mundo, para ele, é o futuro da internet:

As únicas pessoas que serão capazes de manter a liberdade que tínhamos, digamos, vinte anos atrás [...] são aquelas que conhecem intimamente o funcionamento do sistema. Então só uma elite high-tech rebelde é que será livre (ASSANGE, 2013, p. 157).

Esta mensagem é um aviso imediato ao que está acontecendo na rede, mas quem é o personagem que a emite? Julian Assange é um ativista e hacker australiano que se autointitula cypherpunk, ou seja, um militante político que opera através do ciberespaço. Ficou mundialmente conhecido em 2010, quando divulgou, pela WikiLeaks, em parceria com jornais como The Guardian (Grã-Bretanha), Der Spiegel (Alemanha), The New York Times (Estados Unidos), Le Monde (França) e El Pais (Espanha), mais de 70 mil relatórios militares secretos sobre a guerra do Afeganistão - os Diários da Guerra do Afeganistão -; mais de 400 mil relatos de campo na guerra do Iraque - os Registros de Guerra do Iraque - e mais de 250 mil relatórios diplomáticos das embaixadas dos Estados Unidos ao redor do mundo - o Cablegate. Foi o maior vazamento de documentos oficiais da história. Mas o que vem a ser a Wikileaks?

A WikiLeaks é uma organização com características de jornalismo investigativo. Possui uma robusta criptografia para dar anonimato a suas fontes, além de uma incrível base de dados que permite ao leitor ter acesso a milhões de documentos confidenciais em tempo integral, de sua nação e do mundo. São chamadas informações classified (confidenciais), isto é, documentos oficiais arquivados na internet, que podem interferir diretamente no plano material, dado o conteúdo explicitado. São exemplos: o vídeo do helicóptero "Apache"

\footnotetext{
${ }^{1}$ Disponível em: http://www.youtube.com/channel/UCHmLs4VZzdkWgoR3uakHTbA. Acesso em: 12 mai. 2014.
} 
assassinando indivíduos ditos terroristas; os diários das guerras do Afeganistão e Iraque na "luta contra o terror", bem como a opinião de diplomatas estadunidenses acerca de inúmeros governantes mundiais e suas formas de governo.

É acerca destas complexidades na rede virtual que Assange discorre nessa obra. Como o livro acompanha o diálogo sobre inúmeros assuntos relacionados à internet e seu controle, propomos não dividi-lo em capítulos, mas examiná-lo segundo suas características principais, traçando um paralelo com o marco civil no Brasil.

Inicialmente, Assange (2013, p. 20) enfatiza que, "o mundo deve se conscientizar da ameaça da vigilância para a América Latina e para o antigo Terceiro Mundo. A vigilância não constitui um problema apenas para a democracia e para a governança, mas também representa um problema geopolítico”. Neste sentido, são os serviços de segurança do Estado os beneficiários diretos do exercício do poder de controle e repressão. É neste cenário que o projeto de lei marco civil da internet está inserido. Mas do que se trata?

A Lei 12.965/14, conhecida como marco civil da internet, foi analisada e votada pelo Congresso; depois, pelo Senado e, por fim, sancionada pela presidenta Dilma Rousseff, dia 24 de abril de 2014, entrando em vigor dois meses depois, marcando significativamente os direitos à internet no Brasil. Sucintamente, trata-se de uma espécie de constituição de sítio virtual, estabelecendo direitos e deveres para usuários e provedores de internet no País, tais como: neutralidade na rede, ou seja, garantia de que o tráfego terá a mesma qualidade e velocidade, independente do tipo de navegação; não-suspensão da conexão à internet, salvo por débito e sua manutenção da qualidade contratada; privacidade, significando que informações pessoais e registros de acesso só poderão ser vendidos mediante autorização do usuário; segurança dos registros de conexão dos usuários, propondo que os dados sejam guardados pelos provedores durante um ano sob sigilo completo, podendo ser acessados exclusivamente por ordem judicial.

Segundo a coordenadora do Intervozes, Beatriz Barbosa, o principal problema enfrentado pelo marco civil diz respeito ao artigo 15, que obriga as empresas de telecomunicações a guardar, por um ano, todos os dados de tráfego na rede. Segundo a 
pesquisadora, a lei prevê que estas informações só possam ser acessadas por decisão judicial. Mesmo assim, a obrigação:

viola a privacidade do usuário [e] acaba levando ao risco de uma vigilância em massa e é uma limitação à própria liberdade de expressão (que é uma base fundamental do projeto). O fato de saber que toda sua movimentação na internet está sendo armazenada para eventuais investigações faz com que a pessoa se comporte de forma diferente ${ }^{2}$.

Já o coordenador-geral do Sindicato dos Jornalistas Profissionais do Distrito Federal, Jonas Valente, afirma veementemente que, "motivado pela vigilância institucionalizada de um evento internacional, o governo aprova uma lei avançada, mas em que o simples fato de guardar os dados viola a minha privacidade"3. Desses vieses, entendemos que o ponto nevrálgico do marco civil está no artigo 15 da Constituição, ou seja, no armazenamento de dados pessoais que poderiam favorecer a vigilância maciça da internet pelo governo.

A obra de Assange é significativa para tal análise, pois observa que, apesar de estarem constantemente vigiados quando na rede, são os próprios usuários que, muitas vezes, fornecem suas informações particulares. É nesse contexto, permeado de inovações tecnológicas, sobretudo na área informativa, que ocorre a vigilância por parte dos governos e corporações. Uma simbiose de controle e poder que revela o cenário sombrio e orwelliano em que vivemos.

Segundos os cibermilitantes, "o Facebook e a Google podem ser considerados extensões dessas agências, [Uma vez que] têm acesso a todos os dados armazenados" (ASSANGE, 2013, p. 72). Isto significa que, se o sujeito for usuário dessas empresas, as agências de monitoramento, possivelmente, captarão informações como: com quem se comunica, seus interesses e objetivos, até preferência sexual, religiosa e crenças filosóficas. Demodé, o alerta observado por Beatriz Barbosa e Jonas Valente, no que tange ao marco civil, se coaduna com esta análise.

\footnotetext{
${ }^{2}$ Disponível em: http://www.folhapolitica.org/2014/04/apoiadores-do-marco-civil-admitem.html Acesso em: 18 jun. 2014.

${ }^{3}$ Disponível em: http://www.folhapolitica.org/2014/04/apoiadores-do-marco-civil-admitem.html Acesso em: 18 jun. 2014.
} 
Para os cypherpunks, a rede virtual, que há pelo menos 25 anos foi apresentada aos civis como instrumento essencial de dinamização produtiva/reprodutiva das relações capitalistas, se transformou, paulatinamente, em zona de guerra. Para o autor, as mudanças na internet ao longo dos anos modificaram não apenas os relacionamentos interpessoais, mas as formas de ação dos Estados. Consequentemente, as forças governamentais "e seus aliados (corporações) se adiantaram para tomar o controle do nosso novo mundo, se [agarrando] como uma sanguessuga às veias e artérias das nossas novas sociedades" (ASSANGE, 2013, p. 26-27).

A interceptação dessas informações provenientes de todos os rincões do planeta evidencia que todos, indistintamente, são vigiados e o medo é um elemento fundamental para a sustentação desse controle. Desse modo, “é necessário instilar medo nas pessoas para que elas compreendam o problema antes de uma demanda suficiente ser criada para solucioná-lo" (ASSANGE, 2013, p. 83). Noutras palavras, o medo gera lucro, principalmente com o aumento da sofisticação e a redução do custo da vigilância em massa, ou seja, enquanto o crescimento populacional dobra, aproximadamente, a cada 25 anos, a vigilância duplica a cada 18 meses (ASSANGE, 2013, p. 55).

O último viés de discussão é acerca da criptografia, que consiste na prática de se comunicar em código. Esta é uma ferramenta que, segundo os ativistas, pode ser uma arma eficaz de combate à tirania do Estado. Para Sérgio Amadeu, estamos entrando na era da "resistência criptopolítica [onde] a criptografia torna-se instrumento político a ser amplamente incorporado pelos movimentos de resistência ao poder da análise e à biopolítica de modulação executada pelas grandes corporações, de tecnologia e de rede" ${ }^{4}$. Para Assange (2013, p. 27-28), com esse mecanismo:

as pessoas podem se fundir para criar regiões livres das forças repressoras do Estado externo, [...] porque a criptografia [...] não se deixa abalar pela petulância dos Estados nem pelas distopias da vigilância transnacional. [...] A criptografia é a derradeira forma de ação direta não violenta, [pois] é mais fácil criptografar informações do que descriptografá-las.

\footnotetext{
${ }^{4}$ Disponível em: http://www.revistaforum.com.br/digital/137/marco-civil-da-internet-liberdade-na-rede-vai-acabar/ Acesso em: 23 jun. 2014.
} 
Há quem desconfie dos aplicativos criptografados, afirmando que os dados dos usuários já estão sob a tutela de corporações e governos. Esta é a grande polêmica em torno do marco civil da internet no Brasil. O artigo 15 fere o direito à liberdade de expressão? Este decreto limita nosso direito de navegar pela rede? É certo que estamos frente a uma grande encruzilhada, longe de um fim imediato. Diante das condições objetivas suscitadas, a obra de Assange fornece informações cruciais para nos posicionarmos neste cenário histórico, marcado por uma vigilância exacerbada dos meios de comunicação, sobretudo da internet.

\section{Referências}

ASSANGE, J. Cypherpunks: liberdade e o futuro da internet. Trad. Cristina Yamagami. São Paulo: Boitempo, 2013.

BRASIL. Lei 12.965/14, de 23 de abril de 2014. Estabelece princípios, garantias, direitos e deveres para o uso da Internet no Brasil. Disponível em: www.jusbrasil.com.br/legislacao/117197216/lei-n-12-965-de-23-de-abril-de-2014. Acesso em: 23 jun. 2014 . 